Check for updates

Cite this: Environ. Sci.: Processes Impacts, 2021, 23, 776

Received 2nd March 2021 Accepted 20th April 2021

DOI: $10.1039 / \mathrm{d} 1 \mathrm{em} 00102 \mathrm{~g}$

rsc.li/espi

\section{Exploring variations of hexabromocyclododecane concentrations in riverine sediments along the River Medway, UK†}

\begin{abstract}
Benjamin Harris and Mohamed Abou-Elwafa Abdallah (D)*
Surface riverine sediment samples were collected along the course of the River Medway, UK, between Yalding and the mouth of the estuary at 40 different sites. The samples were then analysed for hexabromocyclododecane (HBCDD) concentrations using a liquid chromatography system coupled to a high-resolution, accurate mass Orbitrap ${ }^{T M}$ mass spectrometer. After normalisation to the sediment organic carbon (OC) content, average $\Sigma H B C D D$ was $270 \mathrm{ng} \mathrm{g}^{-1} \mathrm{OC}$ with a maximum concentration of $1006 \mathrm{ng} \mathrm{g}^{-1}$ OC. Spatial trend analysis revealed that industrial and residential land uses have significantly influenced HBCDD concentrations and profiles in riverine sediments. Higher concentrations of $\Sigma$ HBCDD were found in sites near construction and maritime port locations, and these included freight ports, new builds and demolition sites. The HBCDD isomer profile reflected that of the commercial mixture with a comparatively high $\gamma-\mathrm{HBCDD}$ to $\alpha-\mathrm{HBCDD}$ and $\beta-\mathrm{HBCDD}$. The isomer profiles of sites located near construction activities indicate recent pollution events, with increased $\gamma$-HBCDD and decreased $\alpha$ HBCDD compared to the study area's average profile. HBCDD isomer concentrations also indicated that the non-tidal portions of the river caused by locks showed a profile that was typical of older HBCDD contamination, indicating a possible sediment and HBCDD trap.
\end{abstract}

Environmental significance

HBCDD was detected in sediment samples collected along the course of the River Medway, UK, at varying levels, being higher in areas utilised for residential and industrial uses. Elevated levels of HBCDD around construction activities could be attributed to the possible use of HBCDD treated EPS and XPS for thermal insulation of buildings. This was also reflected in the average isomer profile of samples collected near construction areas, showing distinct similarities to the commercial mixture of HBCDD. Although the highest concentration recorded along the Medway was still not sufficient to pose imminent risk to human health, there is still an underlying risk of having such a toxic chemical in locally higher concentration spikes. The isomer profiles of samples in the non-tidal reaches of the Medway also suggested that locks acted as quite effective sediment traps, stopping the flow of HBCDD containing sediment along the river to the ocean.

\section{Introduction}

In the past three decades, a range of brominated flame retardants (BFRs) have been extensively applied to a variety of consumer products to comply with fire safety regulations. The most widely used cycloaliphatic additive flame retardant belonging to this group is hexabromocyclododecane (HBCDD). ${ }^{1}$ HBCDD is utilised as a flame retardant most commonly in expanded (EPS) or extruded polystyrene foam (XPS). Both EPS and XPS are widely used in the construction industry for thermal insulation of buildings. HBCDD is also found to a lesser degree in textiles, carpets and high-impact polystyrene for electronics. ${ }^{2}$ This resulted in an historically high demand for

School of Geography, Earth and Environmental Sciences, University of Birmingham, Birmingham, B15 2TT, UK. E-mail: M.abdallah@bham.ac.uk

$\dagger$ Electronic supplementary information (ESI) available. See DOI: 10.1039/d1em00102g
HBCDD, specifically a global market demand of 31000 tons in 2011, up from 16500 tons a decade earlier in $2001 .{ }^{3} \mathrm{HBCDD}$ has 3 main diastereoisomers, namely $\alpha-, \beta$-, and $\gamma$-HBCDD. In the commercial formulation of HBCDD, the $\gamma$-isomer dominates (75-89\%) with the $\alpha$ - and $\beta$-isomers present in lower amounts (10-13\% and $1-12 \%$, respectively). ${ }^{4}$ In biota, however, the $\alpha$ isomer is found in considerably greater amounts, up to $90 \%$ or more in marine mammals and top predators. ${ }^{5}$ Research has attributed this to several factors including the $\alpha$-isomer having a greater resistance to hepatic cytochrome P450 metabolism than both $\beta$ - and $\gamma$ - HBCDD. ${ }^{6}$ Moreover, the more stable $\alpha$ HBCDD can be formed via the thermal conversion of the $\gamma$ isomer upon exposure to temperatures in excess of $160{ }^{\circ} \mathrm{C}$, which is common during the incorporation of HBCDD into flame-retarded products, as well as photolytically-induced isomerisation which favours the formation of $\alpha$ - HBCDD. ${ }^{7}$ Ultimately, the higher water solubility $\left(49 \mu \mathrm{g} \mathrm{L}^{-1}\right)$, bioavailability and resistance to biological and thermal reactions render the $\alpha$ - 
isomer more persistent in the environment and more bioaccumulative in biota, including humans. ${ }^{8-10}$ Recent studies have shown that HBCDD concentrations in humans can be as high as $36 \mathrm{ng} \mathrm{g}^{-1}$ lipid weight. ${ }^{11}$ This is of concern because the toxicity of HBCDD is indiscriminate to both aquatic and terrestrial organisms, with adverse impacts on the liver and thyroid gland, and increased genetic recombination and neurotoxic effects being recorded as a result of exposure. ${ }^{12,13}$ HBCDD is also known to impact the dopamine system, acting as an inhibitor for dopamine uptake and damaging dopamine neurons, a symptom more commonly known in Parkinson

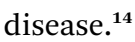

Due to its persistence, bioaccumulative and toxic (PBT) criteria, HBCDD was added to Annex XIV of the European REACH regulation and to Annex A of the Stockholm Convention on POPs. However, this includes a "specific exemption" for its use in EPS and XPS for thermal insulation of buildings. Technically HBCDD can still be produced, utilised, imported and exported until the 25th of December 2021, as long as it is for EPS and XPS or alternatively used for laboratory research., ${ }^{2,15}$ It is therefore still important to research and regulate the amount of HBCDD used globally.

Due to HBCDD treated products being classified as municipal waste rather than hazardous waste, it is treated with less precaution, often being sent to landfills and incinerators. ${ }^{16}$ Consequently, this leaves HBCDD vulnerable to leaching out of products in use or during waste disposal and eventually accumulates in the environment including rivers and water bodies. ${ }^{17}$ This is of importance given that marine environments contribute an estimated $\$ 21$ trillion a year of human welfare to a global gross national product of $\$ 25$ trillion. Despite coastal and shelf systems, such as the River Medway, contributing $60 \%$ of this, they are often viewed by industry as pollution sinks, ${ }^{18}$ and consequently POPs find their way into these water bodies and preferentially accumulate in their organic-rich sediments. Looking specifically at the region of the present study, the southeast of England is of major economic importance not just to the UK but also to wider Europe, with the EU declaring it "internationally-significant", having the second largest economy of any region after London. ${ }^{19}$ Its construction industry specifically is expected to excel, with a predicted yearly growth of $2.2 \%$, higher than that of the wider UK with $1.7 \%$ until $2021{ }^{20}$ Given the exemptions for use of HBCDD in XPS and EPS mentioned above, the potential for significant pollution events to occur due to the expected local growth of the construction sector should not be underestimated.

Previous research on HBCDD in a wide range of riverine sediment samples from across China found a general trend of an increasing concentration from the rural north to the heavily industrialised south east of China. The high concentrations (up to $206 \mathrm{ng} \mathrm{g}^{-1} \mathrm{dw}$ ) in the Yangtze River Delta, Pearl River Delta and southeast area of Fujian Province were linked to the fastest economic and industrial growth in the whole of China, contributing $33.5 \%$ of its GDP. These provinces are unsurprisingly therefore some of the highest polluters, accounting for $30.3 \%$ and $11.5 \%$ of municipal sewage and solid waste, respectively ${ }^{21}$ Similar results were also recorded in the Weihe
River Basin, showing a link between industrial areas, point source pollution and HBCDD concentrations, ${ }^{22}$ and other studies also confirmed that soil and sediment were the primary sink with $\gamma$-HBCDD being the primary isomer in that environmental compartment. ${ }^{3}$ In Europe, Suhring et al. ${ }^{23}$ measured HBCDD in surface sediment samples from the German rivers Elbe and Weser, the German Bight, Jadebusen, East Frisian Coast as well as the southeast coast of the UK. Sediment samples from the river Weser and East Frisian Coast show that HBCDD was not only present, but also reflect the isomer fingerprint of the commercial mixture, with up to $90 \%$ of HBCDD in the $\gamma$-isomer form. Comparatively, sediments from the southern UK coast contained up to $80 \%$ of the $\alpha$-isomer. This was attributed to the abiotic conversion of $\gamma$-to $\alpha$-HBCDD, enhanced under anaerobic conditions. This could indicate an older input of HBCDD to the UK coastal regions. This paper also suggests that HBCDD from the UK is being moved by ocean currents to the East Frisian Coast. ${ }^{23}$ Another study conducted in the UK found varying HBCDD concentrations in Thames river sediment that spiked at very specific points along the industrial areas of the river, with elevated levels of the $\gamma$-isomer, indicating the presence of recent pollution sources. ${ }^{24}$ This illustrates that despite the European and International restrictions on HBCDD, it continues to be a problem in our environment. With previous studies showing a link between industrial water courses and higher HBCDD concentrations, the need to monitor the River Medway becomes more apparent. This is further compounded by the UK Environment Agency admitting significant failures in recording POPs, specifically highlighting $\mathrm{HBCDD}^{25}$ being only monitored in water samples from 13 sites in Kent and the South of London. ${ }^{26}$

Against this backdrop, the present study aims to assess the concentrations of HBCDD main isomers in 40 riverine sediment samples collected along the River Medway, UK. Reasons for variability in concentrations and isomer profiles will be investigated to identify potential sources of HBCDD pollution (e.g. sewage outlets, industrial activities and construction sites) in this highly populated, industrial and economically important river, the Medway.

\section{Materials and methods}

\section{Sample collection and study area}

The River Medway is one of the major water courses in the southeast of England with a catchment area of 930 square miles. With a population of 445346 (ref. 27) and a length of 90 miles including areas of outstanding natural beauty to large managed urban environments with sites of special scientific interest (SSSI) along the river, the Medway is one of the most important wetlands in northern Europe. ${ }^{28}$ The river rises in the High Weald, Sussex, and flows through Tonbridge, Maidstone and the Medway conurbation in Kent, before emptying into the Thames estuary with an overall discharge of $11.08 \mathrm{~m}^{3} \mathrm{~s}^{-1}$. Further information on the physical features/alterations such as locks or bridges, as well as detailed description and maps of the Medway tributaries are reported elsewhere. ${ }^{29}$ 
The sample collection campaign commenced on the 28th of May, 2019 and was completed on the 17th of June, 2019, lasting 3 weeks. One sediment sample was taken at each location shown in Fig. 1 (recorded using a GPS with $\pm 4 \mathrm{~m}$ accuracy) and was accessed by foot. The sample area was divided into two segments by the M2 motorway bridge, between site 40 and site

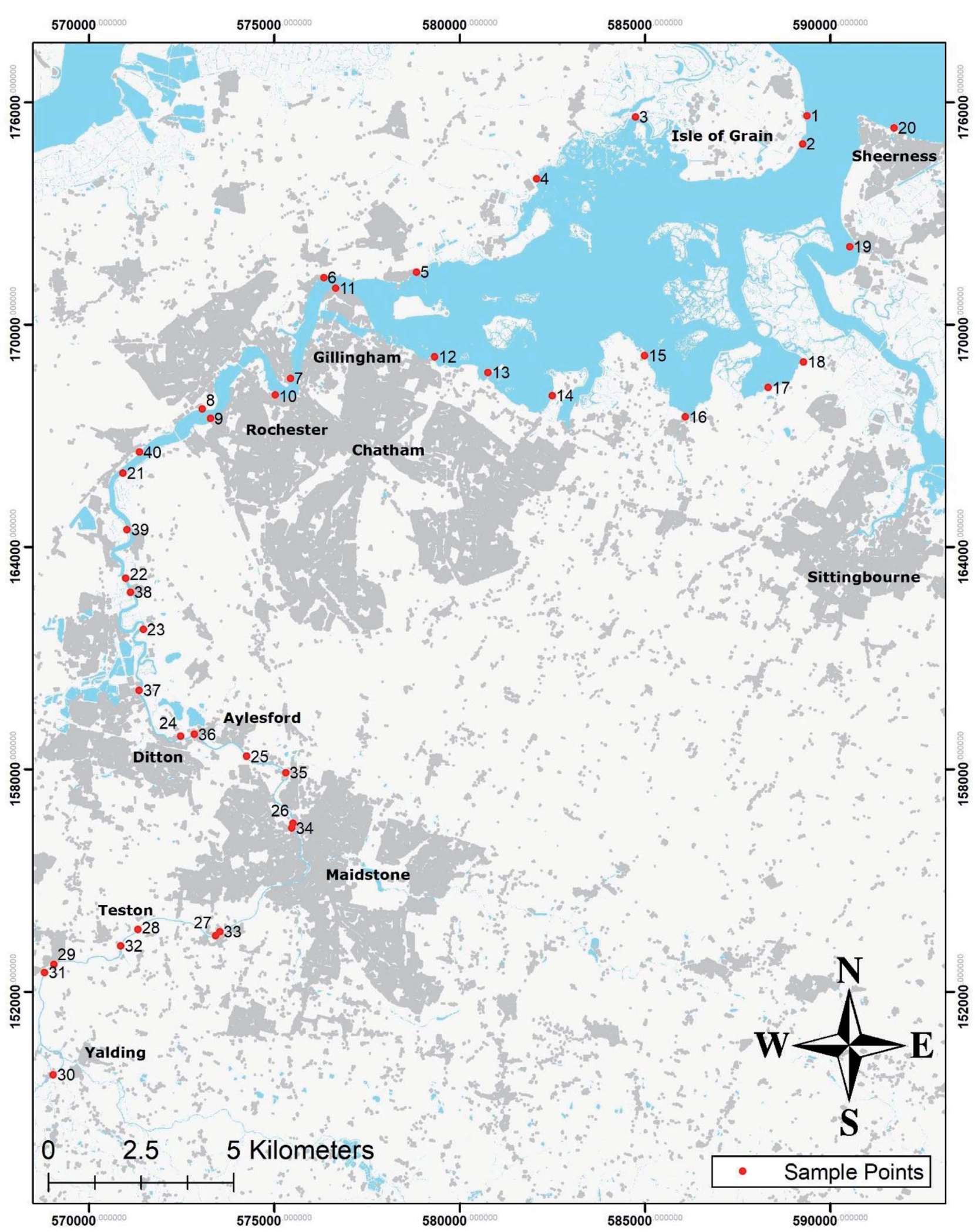

Fig. 1 A map of the study area, the River Medway. The red dots indicate sampling sites. The grey areas show buildings and development. Figures surrounding the map indicate the British National Grid coordinates of the sample area. 
8. This division represents the change in river use from rural and residential to industrial and a physical change from the upper to the lower course of the river. The riverbank length was measured for each segment and 20 sites distributed systematically along it. For the lower course, planned sample points were distributed every $3.87 \mathrm{~km}$ and for upper course every $3.12 \mathrm{~km}$. Ease of access and private land ownership were taken into consideration.

At each location, one sample was taken by the insertion of a sediment corer into the surface sediment ( $5 \mathrm{~cm}$ depth) by foot as far into the river as was safely traversable. The sample was stored in a polyethylene sealable bag and kept in a freezer box until transported to the laboratories in Birmingham. Between sampling, the corer was cleaned using water, spray detergent and a brush so as to avoid cross contamination. At the University of Birmingham, the samples were freeze-dried, sieved through a $2 \mathrm{~mm}$ brass mesh and ground into a fine powder and then stored frozen in clean sealed polyethylene bags until extraction.

\section{Chemical analysis}

The freeze-dried samples were analysed according to a recently reported method. ${ }^{24}$ Briefly, $2 \mathrm{~g}$ of each sample were spiked with $20 \mathrm{ng}$ of the internal (surrogate) standard mixture $\left({ }^{13} \mathrm{C}-\alpha-, \beta-\right.$, and $\gamma$-HBCDDs), along with $2 \mathrm{~g}$ of copper for sulfur removal. Samples were then extracted with hexane : acetone $(3: 1 \mathrm{v} / \mathrm{v})$ using a QuEChERS based method. The crude extract was cleaned up by washing with sulphuric acid, followed by Florisil SPE cartridges. $2 \mu \mathrm{L}$ of the cleaned extract were analysed for HBCDD isomers using a UPLC-Orbitrap-HRMS instrument. This comprised an UltiMate ${ }^{\circledR} 3000$ ultra-performance liquid chromatography system equipped with a HPG-3400RS dual pump, TCC-3000 column oven, and WPS-3000 auto sampler, coupled to a Q-Exactive ${ }^{\mathrm{TM}}$ Plus Orbitrap mass spectrometer. Chromatographic separation was carried out on a Thermo Accucore $^{\mathrm{TM}}$ RP-MS column with the mobile phase consisting of water and methanol. Quantification was performed using Thermo Xcalibur ${ }^{\mathrm{TM}} 3.2$ software. Further details of the analytical method and QA/QC parameters are provided elsewhere ${ }^{24}$ and summarised in the ESI section. $\dagger$

\section{Statistical analysis}

Statistical analysis of the data was carried out using IBM SPSS statistics version 26. The sediment concentrations of HBCDD in dry weight ( $\mathrm{dw}$ ) were normalised to the total organic carbon content (ng g ${ }^{-1}$ OC) to take into account its potential influence (see ESI S1 and Table $\mathrm{S} 1 \uparrow$ for TOC measurements in the studied samples). Sample distribution in the studied datasets was confirmed using a Shaprio-Wilk test. Results revealed our datasets to be log-normally distributed. Therefore, further statistical analysis was conducted on log-transformed data. A one-way ANOVA, Tukey's post-hoc test and $t$-test were used to compare sample means. $P$ value of $<0.05$ was considered statistically significant.

\section{Results}

HBCDD concentrations were above the LOQ (1.5 $\left.\mathrm{pg} \mathrm{g}^{-1} \mathrm{dw}\right)$ in all the studied samples. Good recoveries were observed for the ${ }^{13} \mathrm{C}$ - internal (surrogate) standards ranging from $102-109 \%$ for the 3 studied HBCDD diastereomers (Table SI-2 $\dagger$ ). $\Sigma$ HBCDD concentrations in all the studied sediment samples ranged from 0.7 to $39.1 \mathrm{ng} \mathrm{g}^{-1} \mathrm{dw}$, with an average of $9.1 \mathrm{ng} \mathrm{g}^{-1} \mathrm{dw}$. A statistical summary of the results is provided in Table 1, with the complete set of results provided in the ESI (Table SI-1†).

Table 1 Statistical summary of HBCDD concentrations in the studied area

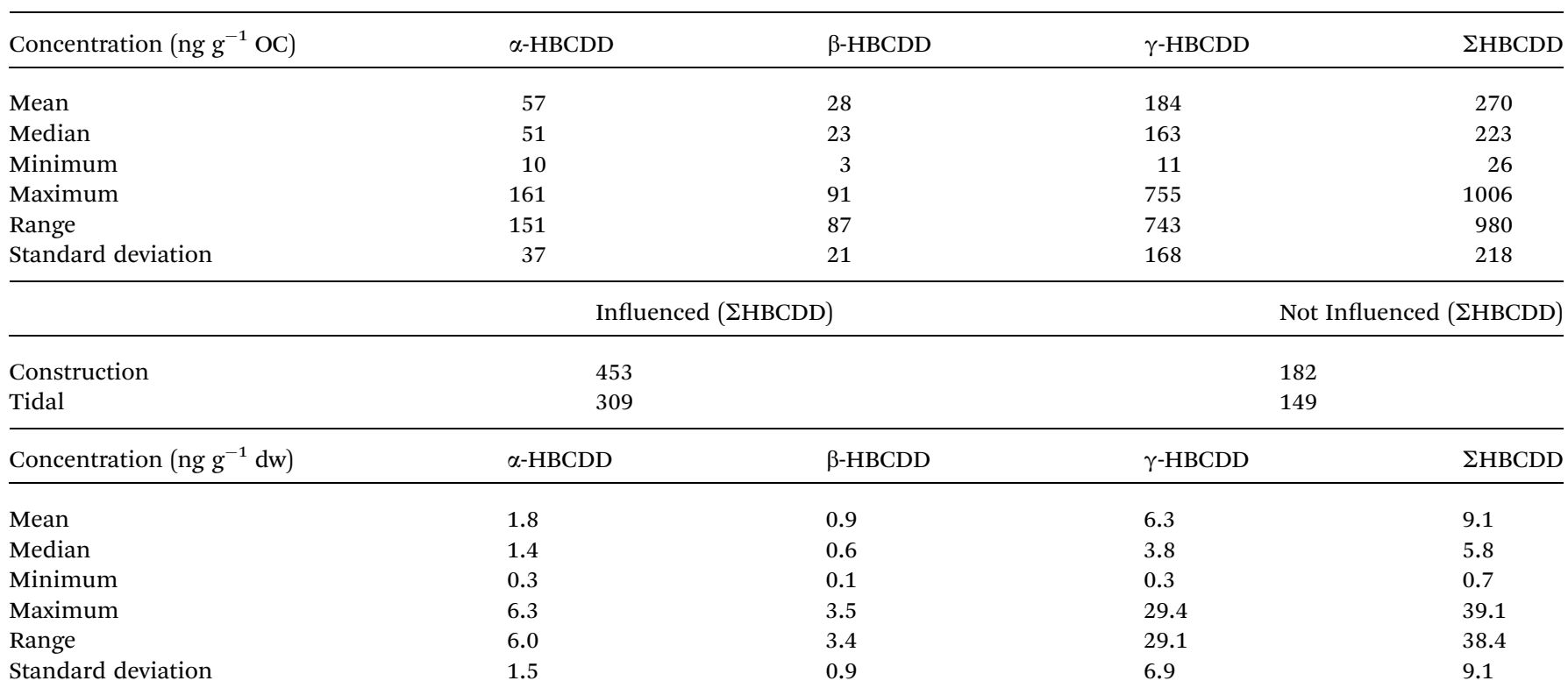


Table 1 shows that the variability of the data collected is reasonably high throughout both TOC- normalized and unnormalized datasets. The low mean compared to the high range and standard deviation indicates that $\Sigma$ HBCDD concentrations increased rapidly in a few selected cases. Table 1 also shows the mean $\Sigma$ HBCDD of sites that could either be influenced by construction activities or tidal regions of the river, respectively.

High variability in $\Sigma$ HBCDD is confirmed when the data is plotted on a distance concentration graph (Fig. 2). This was plotted from the furthest upstream sample site and ran along a distance measured transect through the middle of the river, plotting the corresponding concentrations of $\Sigma$ HBCDD. The graph shows that there is considerable "noise" in the data corresponding to the industrial areas of the river. The residential area however is dominated by two identifiable peaks in concentration while the rural land use area has only one small peak in an otherwise flat line low concentration. Throughout the graph, the standout feature is the rapid increases and decreases in concentration illustrating the high range and standard deviation as shown in Table 1.

An ANOVA test conducted on log-transformed data confirmed that there were significant differences $(P<0.05)$ in $\Sigma$ HBCDD concentrations according to the land-use category as outlined in Fig. 2. A Tukey's post-hoc test revealed that the average $\Sigma$ HBCDD in the rural stretch of the river was significantly lower than the measured average $\Sigma$ HBCDD in residential and industrial areas of the River Medway.

A $t$-test was carried out to investigate the significance of $\Sigma$ HBCDD concentrations between upper (sites 1-20) and lower (21-40) Medway course sample sites (Fig. 1). No significant difference was observed, which may be attributed to the absence of clear differences in physical features and impacts associated with different river course stages (e.g. tidal vs. nontidal) between the upper and lower course sampling sites. However, another $t$-test revealed significantly higher $\Sigma$ HBCDD concentrations in sites impacted by construction activities compared to that of the remaining sites. Further statistical analysis (One-way ANOVA and Tukey's posthoc test) was conducted on individual HBCDD isomer profiles to establish the "HBCDD fingerprint" and investigate the differences in HBCCD isomer distribution profiles between construction influenced and non-construction influenced sites (Fig. 3).

Results revealed a significant difference in HBCDD isomer profiles. Specifically, higher contribution of $\gamma$-HBCDD, together with lower contribution of $\alpha$-HBCDD, was observed in construction influenced sites. The observed HBCDD "fingerprint" in construction influenced sites (Fig. 3a) is more reflective of the isomer profile in HBCDD commercial formulations. ${ }^{5}$ In contrast, sites that were not impacted by construction activities (Fig. $3 \mathrm{~b}$ ) showed higher levels of $\alpha$-HBCDD and lower levels of $\gamma$-HBCDD, while $\beta$-HBCDD levels showed no significant differences.

Another factor that may influence HBCDD levels in the sediment is the tidal nature of the river. Statistical analysis revealed significantly higher $\Sigma$ HBCDD concentrations in tidal sites (Table 1), although no significant differences were observed between HBCDD isomer profiles in tidal and non-tidal sites (Fig. SI-1†).

\section{Discussion}

\section{HBCDD concentrations}

Although there are no UK guidelines for safe HBCDD sediment concentrations, the average and maximum $\Sigma$ HBCDD observed in the Medway surface sediment (Table 1) are all below the environmental quality guidelines such as the Canadian limit of $1.6 \mathrm{mg} \mathrm{kg}{ }^{-1} \cdot{ }^{30}$ This would suggest that adverse health effects are unlikely to immediately arise from the measured HBCDD levels in the Medway. The ecological impact of HBCDD along the river Medway is also likely to be low; earth worms for example have a no observed effect concentration (NOEC) of $59 \mathrm{mg} \mathrm{kg}^{-1}$ dry weight of HBCDD, while most plant species have a NOEC of $5000 \mathrm{mg} \mathrm{kg}{ }^{-1}$ dry weight of HBCDD. ${ }^{31}$ Similarly, the Canadian

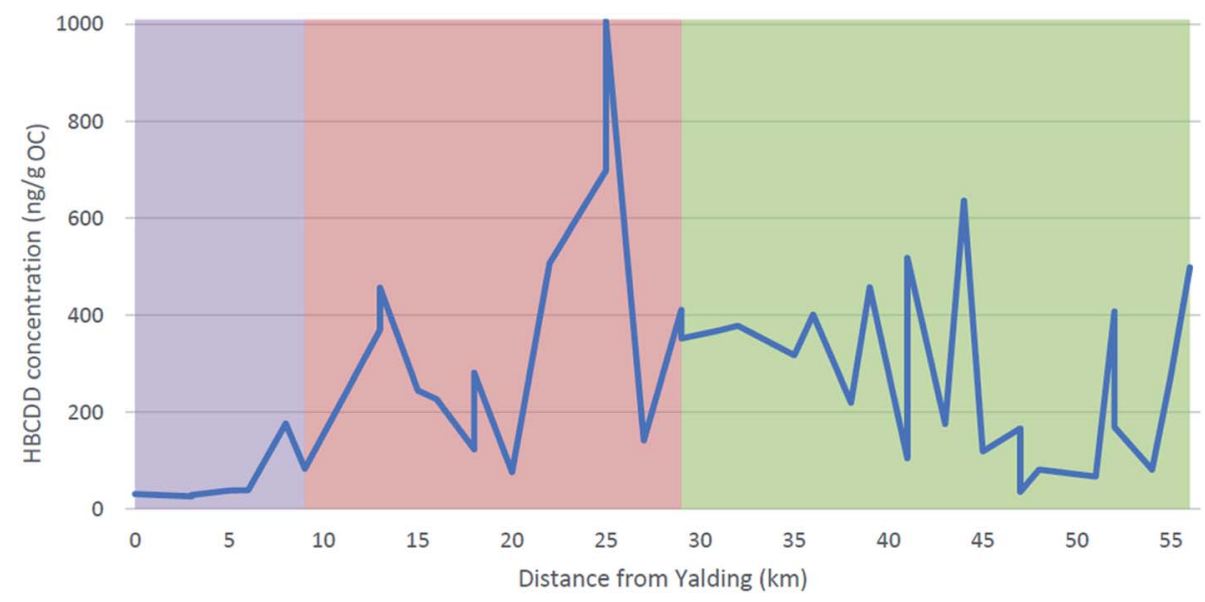

Fig. 2 A distance concentration graph illustrating the changing HBCDD levels along the course of the River Medway. The colour shading of the graph indicates river use categories. The purple area indicates the rural stretch of the river, the red for the residential and green for the industrial portions of the river. 

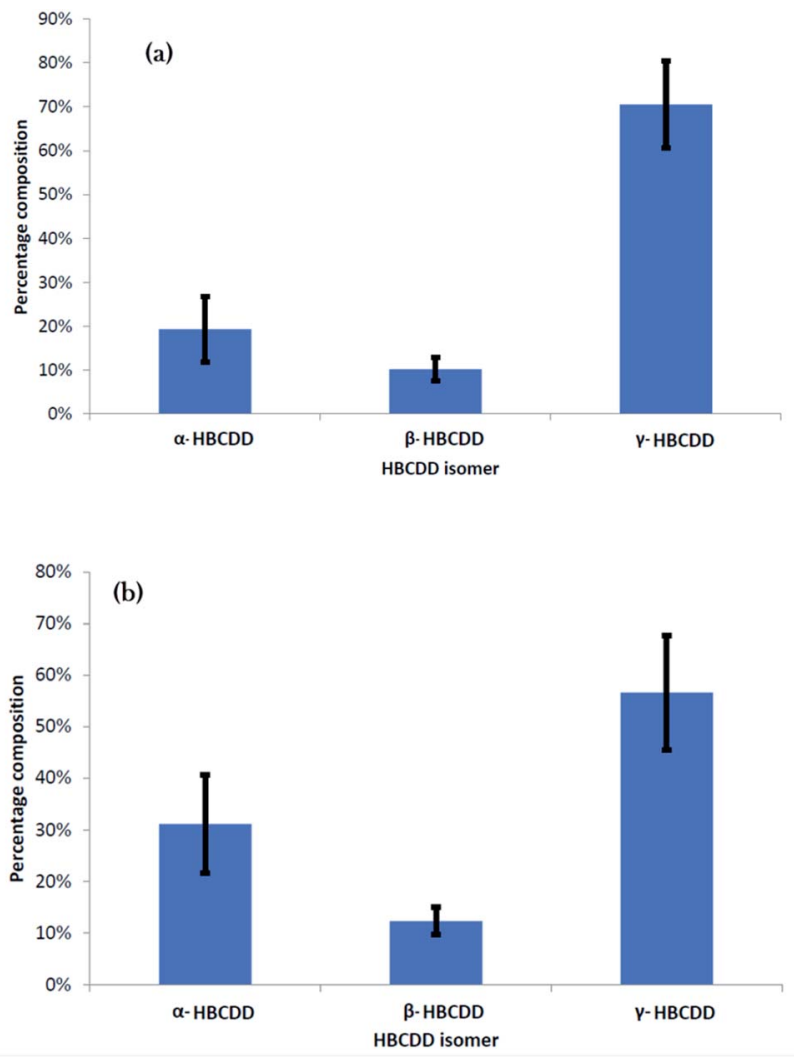

Fig. 3 Average HBCDD isomer profile in (a) construction influenced sites and (b) non-construction influenced sites (bar whiskers represent 1 standard deviation).

sediment quality guideline of $1.6 \mathrm{mg} \mathrm{kg}^{-1}$ was estimated based on HBCDD chronic effects in sediment biota with a NOEC of $8.6 \mathrm{mg} \mathrm{kg}{ }^{-1} \mathrm{dw}$ in Lumbriculus variegatus (total number of worms) and NOEC of $37.8 \mathrm{mg} \mathrm{kg}^{-1} \mathrm{dw}$ in Chironomus riparius (number of eggs). ${ }^{30}$

However, this is not to say that there is no risk. The HBCDD concentrations in river Medwayare in line with, if not above, what the UK Government call a "source location" for HBCDD. In a report for the Department for Environment, Food \& Rural Affairs (DEFRA), sites with a range of $<0.1-30 \mu \mathrm{g} \mathrm{kg}^{-1} \mathrm{dw}$ are considered source locations. ${ }^{31}$ Results gathered in this study show similar but slightly elevated levels of HBCDD. Due to the comparable range of concentrations, the River Medway would appear to show HBCDD levels that are typical of a source location in the UK. This is further backed up by other UK southeast based studies finding similar results. Ganci et al. ${ }^{24}$ found concentrations of HBCDD between $<0.001$ and $38 \mu \mathrm{g} \mathrm{kg}^{-1} \mathrm{dw}$ in surface sediment samples from the river Thames. The greater range of $\Sigma$ HBCDD concentrations in the Thames compared to the present study (Table 1) could be partly explained by the larger study area, and thereby the greater chance of a larger range of concentrations, albeit with a similar mean $\Sigma$ HBCDD concentration $\left(3.7 \mu \mathrm{g} \mathrm{kg}{ }^{-1} \mathrm{dw}\right) .{ }^{24}$ The Medway sediment displayed slightly higher, although broadly similar, concentration values. This is somewhat expected as the River Medway neighbours the river Thames, sharing a headland with much of the same industry and land uses. The higher HBCDD average in the present study could be attributed to the lower number of sites sampled compared to that of the Thames, allowing the few significant peaks in the residential section (Fig. 2) to increase the average. Overall, however, the two rivers show comparable levels of HBCDD, expected when both contain residential and industrial land uses along their respective banks.

The HBCDD concentration found in this study is not, however, similar to that in research conducted in the north of England. A study carried out by Morris $e t a l .{ }^{32}$ in the north of England and Scotland found concentrations ranging from $<2.4-$ $1680 \mu \mathrm{g} \mathrm{kg}^{-1} \mathrm{dw}$ in surface sediments, the highest concentrations originating from the river Skerne. These are considerably higher than those recorded along the River Medway, which can be explained by the location of a BFR manufacturing plant in the neighbouring area. Despite this, other rivers in the north of England and Scotland such as the Tees, Tyne and Clyde showed concentrations up to 511,322 and $187 \mu^{\mathrm{g} \mathrm{kg}}{ }^{-1} \mathrm{dw}$ of HBCDD, respectively. ${ }^{32}$ This is in line with the results of Sühring et al., who reported higher HBCDD concentrations in surface sediment samples collected along the coast of northern England and Scotland compared to the English Channel and southern England. ${ }^{23}$ This may indicate a UK North/South divide in HBCDD concentrations, possibly due to the greater development and subsequent decline of industry in the north of England compared to the south, ${ }^{33}$ leaving many brownfield sites to slowly degrade or be demolished, which is a known source of HBCDD. ${ }^{34}$ Alternatively, this could be explained by the lower average temperatures the north of the UK experiences preventing re-dissolution of HBCDD and allowing its consequential build up in sediments. More research is needed in this area for proper conclusions to be drawn.

\section{Spatial distribution of HBCDD}

The spatial distribution of HBCDD also varies considerably in the studied sampling sites. This can be better explained by the way in which the river and its surrounding land are being used (Fig. 2) rather than the physical characteristics of the course (Fig. 1). Statistical analysis (One-way ANOVA and Tukey's posthoc test) confirmed that the varying levels of $\Sigma$ HBCDD in each land use category (i.e. rural, residential and industrial) were significantly different from one another. The $t$-Test revealed significantly higher concentrations of $\Sigma$ HBCDD in tidal sections of the river (Table 1). In contrast, the $t$-test showed no significant difference in concentrations between the sample areas of upper and lower course (Fig. 1). This would imply that physical course characteristics such as discharge, channel width and fine sediment levels do not have a great influence on HBCDD levels compared to river and land use. These results support the hypothesis that industrial and residential land uses have significantly elevated HBCDD concentrations. ${ }^{24}$ Although the residential portions of the river contain the highest concentrations, the industrial segment of the river contained the "noisiest" data until its gradual decline close to the mouth of the estuary. Rural portions of the river however displayed the lowest concentrations of HBCDD by a considerable margin (Fig. 2). 
This background concentration away from the source illustrates the ability of HBCDD to move from pollution sources into the general environment and therefore impact locations that have not either produced or extensively used HBCDD.

The general trend of increasing HBCDD concentrations in residential and industrial areas has also been observed in other parts of the UK and the world. Along the river Thames, HBCDD was found to increase where industrial activity was taking place. ${ }^{24}$ Further afield in Europe, HBCDD concentrations in riverine sediments showed similar trends on a greater geographical scale in varying industrialisation between the river Rhine and the river Meuse. ${ }^{32}$ In China, studies conducted by $\mathrm{Li}$ et al. also suggested that intensive industrialisation and urbanisation conspicuously increased HBCDD levels in surface sediments collected from seven major rivers. ${ }^{21}$

The concentrations of HBCDD in the industrial portions of the Medway decrease towards the estuary. This can be explained by the gradual inclusion and consequent influence of ocean currents that were absent in the other stages of the river. The influence of ocean currents could increase the rate at which HBCDD-contaminated sediment is removed from the site and dispersed into the open ocean resulting in lower concentrations. ${ }^{24,32}$ However,there are exceptions to this trend; Fig. 2 shows a spike in concentration at the last site sampled along the river, located at the mouth of the estuary next to the North Sea. This abnormal spike of HBCDD can be explained by two potential reasons. The first being the location of a port in Blue Town, a settlement near the sample point. The port predominantly deals with the transportation of goods through large container ships and is home to shipping companies such as SCA Logistics and Peel Ports London Medway. The spike in concentration would indicate that the port could act as a possible pollution source. This explanation is probable; HBCDD has had extensive use in the shipping industry to prevent fires at sea. ${ }^{2}$ Because cargo ships are old,${ }^{35}$ they are likely to have experienced HBCDD use and their consequential presence and minor repair activities at port could account for the elevated HBCDD concentrations. The other possible reason is the location of a nearby Kent County Council recycling plant; there is evidence to suggest that recycling plants unintentionally release $\mathrm{HBCDD}$ into the natural environment ${ }^{36}$ and could offer an explanation to the observed peak.

The peak in concentration ( $408 \mathrm{ng} \mathrm{g}^{-1}$ OC) at site 18 (Fig. 1) is perhaps more unexpected, seen as the second to last peak in Fig. 2 next to the mouth of the estuary. This is unexpected as it goes against the trend of decreasing HBCDD close to the estuary mouth. Moreover, the land use that surrounds the site is predominantly rural, with no recent developments that could act as a pollution source. Due to its geographical location in a cove, it could be subjected to a low energy environment and therefore experience an increase in deposition and build-up of HBCDD contaminated sediment. Further investigation in the form of flow measurements and deposition rates would have to be undertaken to help explain this apparent anomaly.

The highest concentration of $\Sigma$ HBCDD (636 ng g ${ }^{-1}$ OC) in the industrial segment of the river was recorded at site 4 (Fig. 1). Based on the current legislation surrounding the use of
HBCDD, this has two probable explanations. Firstly, the development of the London Medway Commercial Park, ${ }^{37}$ where Amazon has recently built a warehouse. As previously stated, one of HBCDD's largest markets accounting for over $90 \%$ of HBCDD produced has been in XPS and EPS utilised in the construction industry. ${ }^{38}$ The construction of a large-scale commercial infrastructure project has the potential to use such materials in large quantities and thereby risk its unintentional release and leaching into the surrounding environment. Alternatively, the elevated HBCDD levels could also be attributed to the demolition of Kingsnorth power station. The power station was originally constructed in $1963,{ }^{39}$ around the time that HBCDD appeared on the world market ${ }^{40}$ and has undergone a variety of renovations since, increasing the potential for HBCDD use. Its demolition could therefore have released quantities of HBCDD into the surrounding environment.

Other peaks in the industrial portion of the river include sites 11 (458 $\mathrm{ng} \mathrm{g}^{-1}$ OC) and 12 (519 $\mathrm{ng} \mathrm{g}^{-1}$ OC). These could be attributed to the construction of 1700 new homes and related infrastructure on St Marys Island, ${ }^{\mathbf{4 1}}$ somewhere that XPS and EPS would potentially be used. Alternatively, the local port facilities for both pleasure cruising and industrial shipping located between the two sites (part of the aforementioned Peel Ports) could be a contributing factor. According to Peel Ports, their primary import materials are construction based. ${ }^{42}$ It is therefore likely that substantial amounts of flame-retarded materials such as XPS and EPS would have passed through or been stored at this port allowing for possible pollution events in the form of unintentional releases and the mishandling of goods.

Further upstream, the residential portion of the Medway is dominated by the highest concentration of HBCDD found in this study at site 22 (1006 $\mathrm{ng} \mathrm{g}^{-1} \mathrm{OC}$ ). This spike can be explained by the ongoing housing developments of Peters Village based along the banks of the river. The use of XPS and EPS in the construction of Peters village in large quantities is likely, as a whole village is being constructed from scratch. What is alarming however is that an SSSI (Site of Special Scientific Interest) nature reserve is located next to the village. ${ }^{43}$ Considering HBCDD's toxicity and bioaccumulation potential, ${ }^{12,13}$ this may present some threat to wildlife and the surrounding ecosystems. Similarly, the potential implications of such high HBCDD concentrations for human exposure should be considered. A local primary school was built as part of the village plan. ${ }^{44}$ Not only are children more at risk to the potential adverse effects of HBCDD due to their lower body mass, ${ }^{45}$ but research has also shown that classrooms and schools form a major exposure pathway for HBCDD in UK children. ${ }^{46}$ While the elevated HBCDD concentration in the case of Peters Village remains well below the Canadian limit of $1.6 \mathrm{mg} \mathrm{kg}^{-1},{ }^{30}$ careful monitoring of HBCDD is required in this area to avoid any potential health risk to the younger inhabitants of the village.

\section{HBCDD isomer profiles}

Investigation of HBCDD isomer profiles in all the studied sediment samples revealed a dominant $\gamma$ isomer (average percentage contribution to $\Sigma \mathrm{HBCDD}=61.13 \%$ ), a trailing 
$\alpha$ isomer (average contribution to $\Sigma$ HBCDD $=27.28 \%$ ) and $\beta$ isomer (average contribution to $\Sigma$ HBCDD $=11.60 \%$ ). This is in line with the dominance of $\gamma$-HBCDD in the commercial blend used in industrial applications. ${ }^{4}$ This implies that the pollution events have been relatively recent as the $\gamma$ isomer has not yet had time to isomerise into the $\alpha$ isomer and reach an equilibrium dominated by $\alpha$-HBCDD. ${ }^{47}$ Some isomerization however has taken place; the commercial mixture contains slightly higher $\gamma$-HBCDD (75-89\%) and lower $\alpha$-HBCDD (10$13 \%) .{ }^{4}$ Considering that $\alpha$-HBCDD is potentially the most hazardous, bioavailable and most likely to accumulate, ${ }^{48}$ its increased levels are concerning. The fact that $\alpha$-HBCDD concentrations are likely to increase over time as isomerisation takes place indicates that the risk HBCDD poses to human, wildlife and eco system health is also likely to increase.

The construction industry would appear to play a large part in the elevation of HBCDD levels throughout the course of the river Medway (Table 1). This is hardly surprising given the fact that HBCDD is still in use in EPS and XPS, both utilised in the building process. ${ }^{2,7}$ Analysis showed that sample sites across all areas of the Medway that were located near to a construction site had statistically significant $(P<0.05)$ elevated HBCDD concentrations compared to those that were not (Table 1). Further examination of their isomer profiles revealed statistically significant differences. Sites that were located near to known construction/demolition sites had levels that were more in line with the commercial mixture than those that were not (Fig. 3). The levels of $\gamma$-HBCDD increased by $14 \%$ in construction-impacted sites, while their $\alpha$-HBCDD decreased by $12 \%$ on average and $\beta$-HBCDD decreased by $2 \%$. The marked difference in isomer profiles could suggest a fresh pollution input of HBCDD to the sediments sampled at sites located near construction activities. This is evidenced by the HBCDD isomer profile similar to the commercial formulation with predominance of $\gamma$-HBCDD, which didn't have sufficient time to reach the expected $\alpha$-HBCDD dominated equilibrium in the environment via isomerisation and faster degradation of the $\gamma$-isomer compared to $\alpha$-HBCDD. ${ }^{47}$ These findings support the idea that construction activities can be a source of environmental pollution with HBCDD. Similar results were recorded in surface sediments along the Thames; although their construction influenced sites showed a stronger trend of increased $\gamma$-HBCDD and decreased $\alpha$-HBCDD compared to those of the noninfluenced sites. ${ }^{24}$ This suggests that the Thames may have experienced a greater number of recent pollution events than the Medway.

Our results of higher HBCDD levels linked to construction activities raise concern over how to proceed in terms of reducing the impact construction has in the short term until the end of HBCDD use in this sector in $2021 .^{2}$ In addition to the use of "safe" alternatives when available, one possible solution would be to prioritise the use of XPS over EPS. The primary reason being that in the construction industry, HBCDD is generally used in much lower amount in XPS than in EPS, ${ }^{\mathbf{4 9}}$ and therefore can be the lesser of two evils. It's recycling and future use is also important to consider as this is likely to extend past 2021. Research has shown that recycled EPS contains significantly higher levels of HBCDD in products than those made from recycled XPS, ${ }^{50}$ supporting the notion of prioritising the use of XPS over EPS.

Despite the possible actions taken to reduce HBCDD, its future concentrations in the environment are still predicted to increase by organisations such as DEFRA. The majority of buildings currently being demolished or refurbished have been constructed before the widespread use of HBCDD in the UK, while those constructed during widespread use are predicted to become HBCDD emission sources when they are demolished or renovated in the future. ${ }^{31}$ Ultimately more control over how HBCDD-containing products are handled during demolition and renovation are required to stop its release into the environment in light of its expected increase in concentrations.

\section{Conclusion}

HBCDD was detected in sediment samples collected along the course of the River Medway at varying levels, being higher in areas utilised for residential and industrial uses. Elevated levels of HBCDD around construction activities could be attributed to the possible use of HBCDD treated EPS and XPS for thermal insulation of buildings. This was also reflected in the average isomer profile in samples collected near construction areas, showing distinct similarities to the commercial mixture of HBCDD. Although the highest concentration recorded along the Medway was still not sufficient to pose imminent risk to human health, there is still an underlying risk with having such a toxic chemical in locally higher concentration spikes. HBCDD levels in the non-tidal reaches of the Medway also suggested that locks acted as quite effective sediment traps, stopping the flow of HBCDD containing sediment along the river to the ocean. The coincidence of construction locations in non-tidal areas has the potential to cause hazardous concentrations if urban sprawl causes construction projects to be located further upstream. Therefore, more controls over how HBCDD-containing products are handled during demolition and construction activities are required to limit its release into the riverine environment.

\section{Conflicts of interest}

There are no conflicts to declare.

\section{References}

1 M. A. E. Abdallah, Persistent organic pollutants, in Issues in Environmental Science and Technology, ed. R. E. Hester and R. M. Harrison, Royal Society of Chemistry, 2015, vol. 2015January, pp. 150-186.

2 European Maritime Safety Agency (EMSA), Study of two hazardous substances (PFOS and HBCDD) included in the annexes of regulation (EU) 1257/2013 on ship recycling, available at: http://www.emsa.europa.eu/we-do/ sustainability/environment/download/5034/3168/23.html, 2017.

3 Y. Q. Zhang, Y. L. Lu, P. Wang, Q. F. Li, M. Zhang and A. C. Johnson, Transport of Hexabromocyclododecane 
(HBCD) into the soil, water and sediment from a large producer in China, Sci. Total Environ., 2018, 610, 94-100.

4 M. A. E. Abdallah and S. Harrad, Personal exposure to HBCDs and its degradation products via ingestion of indoor dust, Environ. Int., 2009, 35(6), 870-876.

5 A. Covaci, A. C. Gerecke, R. J. Law, S. Voorspoels, M. Kohler, N. V. Heeb, H. Leslie, C. R. Allchin and J. de Boer, Hexabromocyclododecanes (HBCDs) in the environment and humans: A review, Environ. Sci. Technol., 2006, 40(12), 3679-3688.

6 D. T. Szabo, J. J. Diliberto, J. K. Huwe and L. S. Birnbaum, Differences in Tissue Distribution of HBCD Alpha and Gamma between Adult and Developing Mice, Toxicol. Sci., 2011, 123(1), 256-263.

7 M. A. E. Abdallah, M. Bressi, T. Oluseyi and S. Harrad, Hexabromocyclododecane and tetrabromobisphenol-A in indoor dust from France, Kazakhstan and Nigeria: Implications for human exposure, Emerging Contaminants, 2016, 2(2), 73-79.

8 U. Jans, Emerging Brominated Flame Retardants in Sediments and Soils: a Review, Curr. Pollut. Rep., 2016, 2(4), 213-223.

9 N. Maurice, J. C. Olry, R. Cariou, G. Dervilly-Pinel, B. Le Bizec, A. Travel, C. Jondreville and H. Schroeder, Shortterm effects of a perinatal exposure to the HBCDD alphaisomer in rats: Assessment of early motor and sensory development, spontaneous locomotor activity and anxiety in pups, Neurotoxicol. Teratol., 2015, 52, 170-180.

10 M. A. E. Abdallah and S. Harrad, Tetrabromobisphenol-A, hexabromocyclododecane and its degradation products in UK human milk: Relationship to external exposure, Environ. Int., 2011, 37(2), 443-448.

11 D. S. Drage, J. F. Mueller, P. Hobson, F. A. Harden and L. M. L. Toms, Demographic and temporal trends of hexabromocyclododecanes (HBCDD) in an Australian population, Environ. Res., 2017, 152, 192-198.

12 P. Eriksson, C. Fischer, M. Wallin, E. Jakobsson and A. Fredriksson, Impaired behaviour, learning and memory, in adult mice neonatally exposed to hexabromocyclododecane (HBCDD), Environ. Toxicol. Pharmacol., 2006, 21(3), 317-322.

$13 \mathrm{~K}$. Smolarz and A. Berger, Long-term toxicity of hexabromocyclododecane (HBCDD) to the benthic clam Macoma balthica (L.) from the Baltic Sea, Aquat. Toxicol., 2009, 95(3), 239-247.

14 K. R. Genskow, J. M. Bradner, M. M. Hossain, J. R. Richardson and W. M. Caudle, Selective damage to dopaminergic transporters following exposure to the brominated flame retardant, Neurotoxicol. Teratol., 2015, 52, 162-169.

15 M. Sharkey, S. Harrad, M. A. E. Abdallah, D. S. Drage and H. Berresheim, Phasing-out of legacy brominated flame retardants: The UNEP Stockholm Convention and other legislative action worldwide, Environ. Int., 2020, 144.

$16 \mathrm{~W}$. A. Stubbings and S. Harrad, Laboratory studies on leaching of HBCDD from building insulation foams, Emerging Contaminants, 2019, 5, 36-44.
17 C. Bradshaw, A. L. Golz and K. Gustafsson, Coastal Ecosystem Effects of Increased Summer Temperature and Contamination by the Flame Retardant HBCDD, J. Mar. Sci. Eng., 2017, 5(2), 18-38.

18 R. Costanza, The ecological, economic, and social importance of the oceans, Ecol. Econ., 1999, 31(2), 199-213.

19 European Commission, South East of England, available: https://ec.europa.eu/growth/tools-databases/regionalinnovation-monitor/base-profile/south-east-england, 2019.

20 Construction Industrial Training Board (CITB), Construction Skills Network Forecasts 2017-2021, available at: https:// www.citb.co.uk/documents/research/csn\%202017-2021/csnnational-2017.pdf, 2016.

21 H. H. Li, H. T. Shang, P. Wang, Y. W. Wang, H. D. Zhang, Q. H. Zhang and G. B. Jiang, Occurrence and distribution of hexabromocyclododecane in sediments from seven major river drainage basins in China, J. Environ. Sci., 2013, 25(1), 69-76.

22 X. L. Wang, X. Y. Yuan, S. K. Yang and Y. Q. Zhao, Concentrations, Distributions, and Risk Assessment of HBCD in Sediment in the Weihe River Basin in Northwest China, Int. J. Environ. Res. Public Health, 2018, 15(11), 2340-2351.

23 R. Suhring, J. L. Barber, H. Wolschke, D. Kotke and R. Ebinghaus, Fingerprint analysis of brominated flame retardants and Dechloranes in North Sea sediments, Environ. Res., 2015, 140, 569-578.

24 A. P. Ganci, C. H. Vane, M. A. E. Abdallah, T. Moehring and S. Harrad, Legacy PBDEs and NBFRs in sediments of the tidal River Thames using liquid chromatography coupled to a high resolution accurate mass Orbitrap mass spectrometer, Sci. Total Environ., 2019, 658, 1355-1366.

25 Environment Agency, Water Quality. The state of the environment, 2018, vol. 1, pp. 1-12, available at: https:// www.gov.uk/government/publications/state-of-theenvironment.

26 Environment Agency, Open water quality archive datasets, available at: https://environment.data.gov.uk/water-quality/ view/download/new, 2019.

27 Office for National Statistics, Population Estimates for UK, England and Wales, Scotland and Northern Ireland, 2017, available at: https:/www.ons.gov.uk/datasets/mid-year-popest/editions/time-series/versions/4.

28 Environment Agency, A summary of information about the water environment in the Medway management catchment, The Medway Management Catchment, 2014, vol. 1, pp. 1-79, available at: https://environment.data.gov.uk/ catchment-planning/ManagementCatchment/3055.

29 Environment Agency, River Medway: bridges, locks and facilities for boaters, 2019, available at: https:/www.gov.uk/ guidance/river-medway-bridges-locks-and-facilities-forboaters.

30 Environment Canada, Canadian Environmental Protection Act, 1999 Federal Environmental Quality Guidelines Hexabromocyclododecane (HBCD), 2016, pp. 1-8, available at: https:/www.ec.gc.ca/ese-ees/default.asp? lang $=\mathrm{En} \& \mathrm{n}=8 \mathrm{BA} 57 \mathrm{E} 1 \mathrm{C}-1$. 
31 M. Broomfield; R. Whiting; V. Lupi and G. Jones, Costs and Benefits of the Addition of Hexabromocyclododecane (HBCD) to the Stockholm Convention and the 1998 POPs Protocols, Report for Department for Environment, Food and Rural Affairs, 2010, vol. 5, pp. 1-60, available at: http:// randd.defra.gov.uk/Document.aspx?Document= ED56226CostBenefitHBCDReportCND0101 Oct2010v16FINAL.PDF.

32 S. Morris, C. R. Allchin, B. N. Zegers, J. J. H. Haftka, J. P. Boon, C. Belpaire, P. E. G. Leonards, S. P. J. Van Leeuwen and J. De Boer, Distributon and fate of HBCD and TBBPA brominated flame retardants in north sea estuaries and aquatic food webs, Environ. Sci. Technol., 2004, 38(21), 5497-5504.

33 R. Lupton and A. Power, The Growth and Decline of Cities and Regions, Case-Brookings Census Briefs, 2004, vol. 1, pp. 1-15, available at: http://eprints.lse.ac.uk/id/eprint/27358.

34 Ministry of Infrastructure and the Environment The Netherlands, HBCDD in EPS/XPS waste in the Netherlands, Inventory of size and value, 2016, pp. 1-68, available at: http://chm.pops.int/Portals/0/download.aspx?d=UNEPPOPS-HBCDD-EPSXPSWaste-Netherlands20161222.English.pdf.

35 United Nations Conference on Trade and Development, Review of maritime transport, 2018, available at: https:// unctad.org/en/PublicationsLibrary/rmt2018_en.pdf.

36 Y. Liu, X. J. Luo, Y. H. Zeng, M. Deng, W. Q. Tu, Y. M. Wu and B. X. Mai, Bioaccumulation and biomagnification of hexabromocyclododecane (HBCDD) in insect-dominated food webs from a former e-waste recycling site in South China, Chemosphere, 2020, 240.

37 Goodman, London Medway Commercial Park, 2019, available: https://uk.goodman.com/london-medwaycommercial-park.

38 Z. Q. Nie, Z. L. Yang, Y. Y. Fang, Y. F. Yang, Z. W. Tang, X. R. Wang, Q. Q. Die, X. B. Gao, F. S. Zhang, Q. Wang and Q. F. Huang, Environmental risks of HBCDD from construction and demolition waste: a contemporary and future issue, Environ. Sci. Pollut. Res., 2015, 22(21), 1724917252 .
39 S. Newsome; E. Carpenter and P. Kendall, The Hoo Peninsula Landscape, Historic England, 2015.

40 United Nations Environment Programme (UNEP), Risk management evaluation on HBCD, 2011, available at: http:// chm.pops.int/Portals/0/download.aspx?d=UNEP-POPS-

POPRC.7-19-Add.1.English.pdf.

41 Countryside, St Mary's Island, 2020, available at: https:// www.countrysideproperties.com/case-study/st-marys-island.

42 Peel Ports, London Medway, 2016, available at: https:// www.peelports.com/ports/london-medway.

43 Natural England, Sites of Special Scientific Interest, 2020, available at: https:/www.gov.uk/guidance/protected-areassites-of-special-scientific-interest.

44 Trenport Peters Village Ltd., Peters Village Site Plan, 2018, available at: https://petersvillage.co.uk/page/site-plan.

$45 \mathrm{M}$. A. E. Abdallah, S. Harrad and A. Covaci, Hexabromocyclododecanes and tetrabromobisphenol-A in indoor air and dust in Birmingham, UK: Implications for human exposure, Environ. Sci. Technol., 2008, 42(18), 68556861.

46 S. Harrad, E. Goosey, J. Desborough, M. A. E. Abdallah, L. Roosens and A. Covaci, Dust from UK Primary School Classrooms and Daycare Centers: The Significance of Dust As a Pathway of Exposure of Young UK Children to Brominated Flame Retardants and Polychlorinated Biphenyls, Environ. Sci. Technol., 2010, 44(11), 4198-4202.

47 M. Weber, R. Becker, V. Durmaz and R. Koppen, Classical hybrid Monte-Carlo simulation of the interconversion of hexabromocyclododecane stereoisomers, Mol. Simul., 2008, 34(7), 727-736.

48 J. M. Sanders, G. A. Knudsen and L. S. Birnbaum, The Fate of $\beta$-Hexabromocyclododecane in Female C57BL/6 Mice, Toxicol. Sci., 2013, 134(2), 251-257.

49 M. Rani, W. J. Shim, G. M. Han, M. Jang, Y. K. Song and S. H. Hong, Hexabromocyclododecane in polystyrene based consumer products: An evidence of unregulated use, Chemosphere, 2014, 110, 111-119.

50 M. A. E. Abdallah, M. Sharkey, H. Berresheim and S. Harrad, Hexabromocyclododecane in polystyrene packaging: A downside of recycling?, Chemosphere, 2018, 199, 612-616. 